\title{
Spatial and temporal differentiation characteristics of soil erosion of highway slope in the permafrost region of the Qinghai-Tibet Plateau
}

\author{
Xiaofeng Zhang ${ }^{1}$, Jinru $\mathrm{Hu}^{1, *}$, Hongjun $\mathrm{Li}^{1}$, Xiaochun Qin², Yaokai Wang ${ }^{2}$, Rui Wang ${ }^{3}$ \\ ${ }^{1}$ China Academy of Transportation Sciences, Beijing, 100029, China \\ ${ }^{2}$ School of civil and architectural engineering, Beijing Jiaotong University, Beijing, 100044, China \\ ${ }^{3}$ Beijing Forestry University, Beijing, 100083, China
}

\begin{abstract}
In order to learn the relevant characteristics of soil erosion of highway slope in the permafrost region of the Qinghai-Tibet Plateau, the different characteristics of the erosion area were analyzed in this paper firstly. Then based on ArcGIS and RUSLE modes and gray correlation analysis, the spatial and temporal differentiation characteristics of soil erosion in the area were proposed. The results showed that soil erosion was mainly concentrated in June to September, and the date of the project construction should be avoided as much as possible; The erosion intensity was slightly and mildly and gradually weakened from south to north. Theoretical research results will have important theoretical and technical significance for the prevention and control of soil erosion of highway slope in the permafrost area of the Qinghai-Tibet Plateau.
\end{abstract}

\section{Introduction}

Due to global climate change and the westward shift of national development strategy, the intensification of permafrost melting, the degradation of high-cold meadows and grassland vegetation, the intensification of soil erosion, and the rapid development of soil desertification had been experienced in the Qinghai-Tibet Plateau. The study found that the potential soil erosion of the ecosystems of the Qinghai-Tibet Plateau was as high as $3.09 \times 1010 \mathrm{t} / \mathrm{a}^{[1]}$, and the economic value of soil conservation function was $1.5 \times 108-4.6 \times 108 \mathrm{RMB} / \mathrm{a}$ for the high-cold meadow ecosystem ${ }^{[2]}$. The economic value of soil conservation function in the whole region was $5.95 \times 108 \mathrm{RMB} / \mathrm{a}^{[1]}$. Therefore, soil erosion had a profound impact on the ecology and environment of the sensitive and fragile Qinghai-Tibet Plateau.

There were many studies on soil erosion in the Qinghai-Tibet Plateau area, but they mainly focus on the space-time changes of small-scale soil erosion, or on the soil conservation function and its value of ecosystems, or on soil erosion of a single ecosystem type, as well as the control factors of small-scale soil erosion, and there was little research on permafrost areas of the Qinghai-Tibet Plateau. In this topic, we first summarized the erosion area difference characteristics of the permafrost area of the Qinghai-Tibet Plateau, and then, based on ArcGIS and RUSLE models, as well as the mapping of topographical features, vegetation and other factors or remote sensing data and the classification criteria according to soil erosion, to reveal the space-time and space-time separation characteristics of the permafrost area of the Qinghai-Tibet Plateau.

\section{Erosion area difference characteristics}

\subsection{Erosion type}

The geographical and environmental characteristics of the Qinghai-Tibet Plateau determined the diversity of soil erosion types and the complexity of erosion patterns. Freeze-thaw erosion, water erosion, and wind erosion were evident in this area by the nature of the agent. These types of erosion tend to interact.

2.1.1 Freeze-thaw erosion. The high altitude and high climate of the Qinghai-Tibet Plateau were one of the main types of soil erosion in the Qinghai-Tibet Plateau. The Qinghai-Tibet Plateau area was about $2 / 3$ of the area, with an average annual temperature below 0 degrees centigrade. The whole year freeze period inside the plateau was up to $7-8$ months, and the day was very poor, mostly in the 15 degrees centigrade or $\mathrm{so}^{[3]}$, even in the permafrost melting season, it was possible to have the alternating effect of day and night freezing and melting. Therefore, in the QinghaiTibet Plateau, hot melting slip, melting mud flow and frozen melt stripping of the turf layer were more common and serious damage to the form of freeze-thaw erosion.

2.1.2 Water erosion. Hydraulic erosion occurred mainly in poor vegetation on wasteland, dredging

\footnotetext{
*Corresponding author: hjr158@126.com
} 
grasslands and sloped farmland, while the cliffs on both sides of steep and ravine were dominated by gravity erosion such as landslides and slippery water. The precipitation in this area was less overall, and the precipitation was more than moderate rain, less heavy rain, but the precipitation was mainly concentrated in JuneSeptember, accounting for more than $80 \%$ of the whole year, the greater intensity of moderate rain easily cause soil erosion. Most of the Qinghai-Tibet Plateau soil layer was thin and the gravel loose accumulation, due to precipitation and flowing water, so that ditches, rivers, slopes, valleys coexist. At the same time, severely affected by human activities

2.1.3 Wind erosion. The Qinghai-Tibet Plateau was one of the most widely distributed areas of wind erosion in China. In the south of Kunlun Mountain, Shenzha Qumalai line west, above $4000 \mathrm{~m}$ above sea level, the average annual wind days were more than 100 days ${ }^{[3]}$. Especially in Qaidam, Qinghai Lake, The Republican Basin and other areas, due to the lack of precipitation, dry erosion and wind effects were very strong, so the wind erosion landscape was very developed.

\subsection{Erosion area difference characteristics}

Different climatic factors were the main external forces for soil erosion in the Qinghai-Tibet Plateau, and the type and distribution of soil erosion were determined. The space-time distribution of precipitation determined that the effect of water erosion weakened from southeast to northwest, and the wind effect was gradually strengthened, and the effect of freeze-thaw erosion was gradually weakened around the center of the Qiangtang Plateau. Southern Tibet was the main agricultural area in Tibet, the soil was more developed, the slope of the ground was large, and the slope was seriously washed away. Eastern Tibet and western Sichuan had more precipitation, with an average annual rainfall of $800 \mathrm{~mm}$. Due to strong cutting by the action of flowing water, landslides and mudslides were common. The average annual precipitation of the Huangshui and Yellow River Valleys was $500 \mathrm{~mm}$, which was covered by loess, and had strong water erosion and step-by-step development. In Naqu - Yushu area, the average annual temperature was 0 degrees centigrade, and the average annual precipitation was $500 \mathrm{~mm}$. Gangdise Nyenchen Tanglha Mountain north, south of Kunlun Mountain, and west of Ando-Mado, the climate was cold and dry, and the flowing water was weak, and the freezing and thawing effect was strong, and the ice edge geomorphology was developed, while there always had high winds. The temperature of The Qaidam Basin was high, and the precipitation was very small, and the soil erosion was mainly by wind erosion. Kunlun Mountain Altun Mountain - Qilian Mountain north wing precipitation was scarce, mainly by the role of high mountain meltwater and wind.

\section{Time-difference characteristics of soil erosion}

Due to seasonal changes in conditions such as rainfall and temperature, the intensity of soil erosion was bound to change over time. At the same time, due to the regional differences of geographical environment, the law of change of soil and water loss over time will also show obvious regional characteristics, so it was important to study and understand the time difference characteristics of soil erosion in the Qinghai-Tibet Plateau region.

\subsection{Time-difference characteristics of soil erosion}

Luo Lifang et $\mathrm{al}^{[4]}$ through the annual changes of rainfall, runoff and sediment in Golmud and Xiangda stations, they were concluded that soil erosion in the Qinghai-Tibet Plateau region occurred mainly in June-September, accounting for $87 \%$ and $94 \%$ respectively, and the soil erosion was very weak in the rest of the time period. But the June to September was also the prime time of the project construction, which showed the importance of strengthening soil and water conservation in the construction of the Qinghai-Tibet Plateau. At the same time, as far as possible to avoid the serious soil erosion season, in order to reduce the damage caused to the environment caused by the construction of the project. This characteristic cannot be ignored when analyzing and estimating the new soil erosion in the construction of the project.

\subsection{The main influencing factors affecting the difference of soil and water loss}

The main factors affecting the difference of soil and water loss were precipitation and vegetation. Increased coverage of major vegetation ecosystems was conducive to reducing soil erosion, but changed in rainfall dominated the changes in soil erosion.

\subsubsection{Precipitation factor. Differences in spatial} distribution of precipitation: There were three relatively heavy precipitation centers on the Qinghai-Tibet Plateau, located in Xining City, Nyingchi and the southern part of Shigatse. The average annual precipitation of these three precipitation centers was more than $450 \mathrm{~mm}$, of which the precipitation center in Nyingchi had the largest annual precipitation, more than $850 \mathrm{~mm}$. In addition, there was a relatively little rain area in the area around Changdu. Located in the northwest and northern parts of the Qinghai-Tibet Plateau, the annual precipitation is relatively small: the Shiquan River and its northern region annual precipitation was below $200 \mathrm{~mm}$, while the average annual precipitation in the Qaidam basin area in the northern highlands was less than $100 \mathrm{~mm}$, which was the driest region of the plateau.

Difference in time distribution of precipitation: the study of precipitation changes in different periods showed that the precipitation in the Qinghai-Tibet Plateau from 
1971 to 2000 displayed a trend of decreasing precipitation

Table 1 that the precipitation in the permafrost area of the Qinghai-Tibet Plateau was less overall, mainly concentrated in May-October, accounting for more than $80 \%$ of the annual precipitation, with a maximum of $67.8 \mathrm{~mm}$. The precipitation in summer and autumn was significantly higher than that of spring and winter. The from its southeast to the northwest ${ }^{[5]}$. It can be seen in precipitation in February-April was 0.9-12.6mm, although the spring thawing period rainfall is not large, but raindrop splashing and runoff erosion can still be caused to soil on slopes with incomplete thawing and poor permeability. Therefore, precipitation was one of the key factors leading to soil erosion on highway slopes.

Table 1.Meteorological conditions for the 2017 permafrost experimental station

\begin{tabular}{cccccc}
\hline In 2017 & $\begin{array}{c}\text { Monthly } \\
\text { precipitation }\end{array}$ & $\begin{array}{c}\text { Average } \\
\text { temperature }\end{array}$ & $\begin{array}{c}\text { Daily } \\
\text { precipitation } \\
0.1 \mathrm{~mm}\end{array}$ & $\begin{array}{c}\text { Maximum wind } \\
\text { speed }\end{array}$ & $\begin{array}{c}\text { Maximum } \\
\text { daily } \\
\text { precipitation }\end{array}$ \\
\hline January & $\mathrm{mm}$ & ${ }^{\circ} \mathrm{C}$ & day & $\mathrm{m} / \mathrm{s}$ & $\mathrm{mm}$ \\
February & 2.4 & -17.21 & 3 & 13.5 & 1.9 \\
March & 0.9 & -10 & 2 & 14.4 & 0.6 \\
April & 12.6 & -8.15 & 10 & 14.3 & 2.9 \\
May & 5.9 & -1.47 & 3 & 12.2 & 3.4 \\
June & 32.5 & 1.5 & 11 & 11.5 & 12.7 \\
July & 38.2 & 5.2 & 14 & 12.8 & 11.7 \\
August & 77.9 & 9.8 & 13 & 13.8 & 15.7 \\
September & 72.2 & 9 & 15 & 11.3 & 12.5 \\
October & 67.8 & 4.8 & 22 & 10.6 & 8.1 \\
November & 35.2 & -0.7 & 14 & 11.8 & 14.6 \\
December & 7.6 & -10.5 & 6 & 9.5 & 2.6 \\
\hline
\end{tabular}

3.2.2 Vegetation factor. The cover space of the surface vegetation of the Qinghai-Tibet Plateau was decreasing from southeast to northwest. The area with high vegetation cover was located in the southeast, central and eastern part of the plateau, where the precipitation was high and the temperature was high, and the combination of water and heat was suitable for the growth of subtropical vegetation, and the vegetation was mainly conifer, and the cover was very high.; The middle and east of the plateau was the source of the three rivers, and the river network was dense, and the surface water was rich, and the vegetation was mainly high cold meadow, and the cover was high. With the extension to the northwest inland, precipitation decreased significantly, and the surface vegetation became more and more sparse, and the vegetation types were the high cold desert mainly, with the low coverage. The surface of the Tibetan-north plateau area was basically covered without vegetation, and it was mostly bare soil, bare rock, Gobi, desert, etc. ${ }^{[6][7]}$. In terms of changes in vegetation cover and soil erosion, Kang Linqi et al ${ }^{[8]}$ were concluded that the high-altitude, low temperature, low vegetation cover, and significant increase in rainfall had led to a significant increase in soil erosion in the relatively fragile ecosystem of high-cold grassland ecosystems. So the vegetation factor also leaded to soil erosion on highway slopes.

\section{The spatial difference characteristics of soil erosion}

It is useful to use RUSLE model to study the intensity of erosion at the regional scale in the Qinghai-Tibet Plateau region, and in recent years, several scholars had carried out research and discussion on soil erosion monitoring and spatial distribution of soil erosion in different parts of the Qinghai-Tibet Plateau using GIS and RUSLE models. However, the study of soil erosion characteristics in the permafrost area of the Qinghai-Tibet Plateau was still blank. Therefore, in this paper, the RUSLE model was used to study soil erosion characteristics in the permafrost area of the Qinghai-Tibet Plateau (It is shown in Figure labout the location of the study area). 


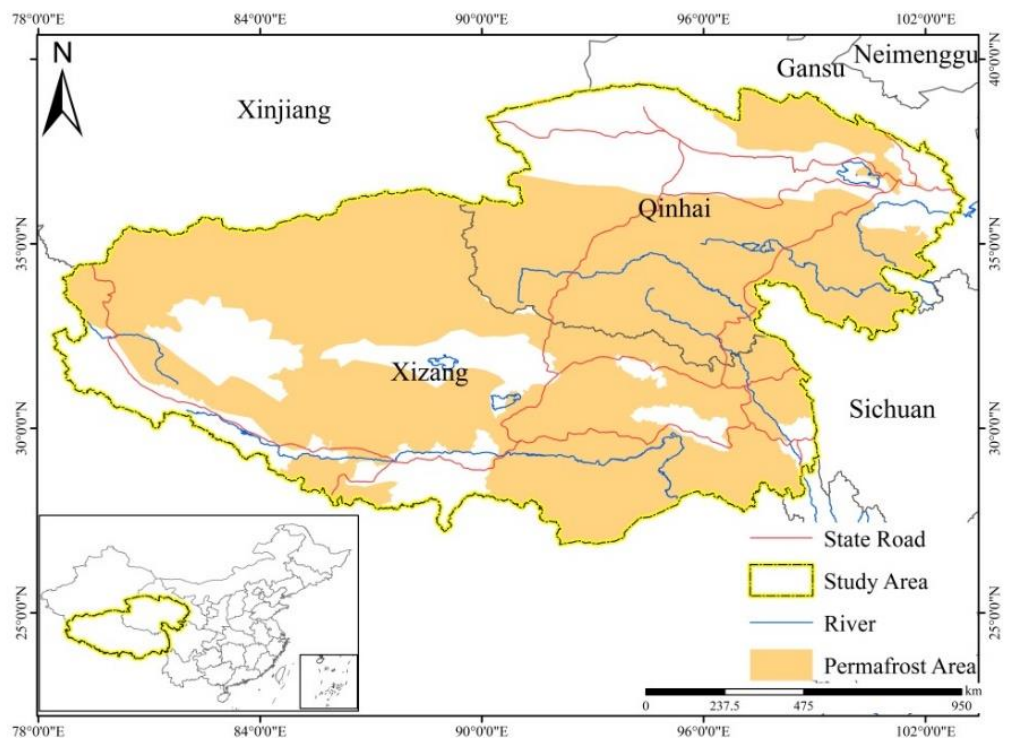

Figure 1 .Regional scope and national highway network

Note: National roads in the study area include: State Road 109, State Road 214, State Road 215, State Road 219, State Road 227, State Road 315, State Road 317, State Road 318.

\subsection{RUSLE model of permafrost area of Qinghai-Tibet Plateau}

The raw data needed to establish the RUSLE model mainly include rainfall, soil attribute, DEM, land use and NDVI and so on. The data were mainly from China Meteorological Data Network, the Chinese Academy of Sciences Resource environmental science data center, and the Chinese Academy of Sciences cold zone dry zone science data center and so on. Data processing and analysis were carried out by using ArcGIS projection conversion, grid cutting, maximum synthesis, reclassification, raster calculator, slope analysis, grid fusion, etc. RUSLE's expression was ${ }^{[9]}$ :

$$
\mathrm{A}=\mathrm{R} \cdot \mathrm{K} \cdot \mathrm{LS} \cdot \mathrm{C} \cdot \mathrm{P}
$$

Type: A - Annual soil loss, $\mathrm{t} / \mathrm{hm}^{2} \cdot \mathrm{a}$; R-Rainfall-Runoff erosion factor, $\mathrm{MJ} \cdot \mathrm{mm} / \mathrm{hm}^{2} \cdot \mathrm{h} \cdot \mathrm{a} ; \mathrm{K}$ - Soil corrosion factor, $\mathrm{t} \cdot \mathrm{hm}^{2} \cdot \mathrm{h} / \mathrm{hm}^{2} \cdot \mathrm{MJ} \cdot \mathrm{mm} ; \mathrm{LS}$ - Slope length, slope factor, no volume outline; C-Coverage-management factors, no volume outline; $\mathrm{P}$ - Water and soil conservation measures factor, no amount of outline.
4.1.1 Rainfall erosion $(R)$ factor. Rainfall erosion $\mathrm{R}$ refers to the scouring force of the surface soil during rainfall (snow) subsidence. According to the uneven distribution of rainfall and soil erosion in Qinghai and Tibet, the rainfall erosion $\mathrm{R}$ was calculated using rainfall statistics. The calculation formula was as follows:

$$
\mathrm{R}=0.04830 \mathrm{P}^{1.610}
$$

Type: R-Year Rainfall Erosion $(\mathrm{MJ} \cdot \mathrm{mm}) /\left(\mathrm{hm}^{2} \cdot \mathrm{h} \cdot \mathrm{a}\right)$; P - Annual rainfall (mm)

Using GIS calculation results showed that the range of $\mathrm{R}$ values is $19.3531-3050 \mathrm{MJ} \cdot \mathrm{mm} / \mathrm{hm}^{2} \cdot \mathrm{h} \cdot \mathrm{a}$. The $\mathrm{R}$ value in the study area was shown that the south was higher than the north and the east was higher than the west and the high-altitude areas such as the Transverse Mountains in the South-East had the Higher R values $(\mathrm{R}>1000)$. And $\mathrm{R}$ values were distributed in coastal areas, consistent with the study area. From the point of view of regional vertical distribution, the $\mathrm{R}$ value decreases with the decline of altitude, and the peak occurred in the southeast of the study area, which belonged to the southern part of the Cuona county.

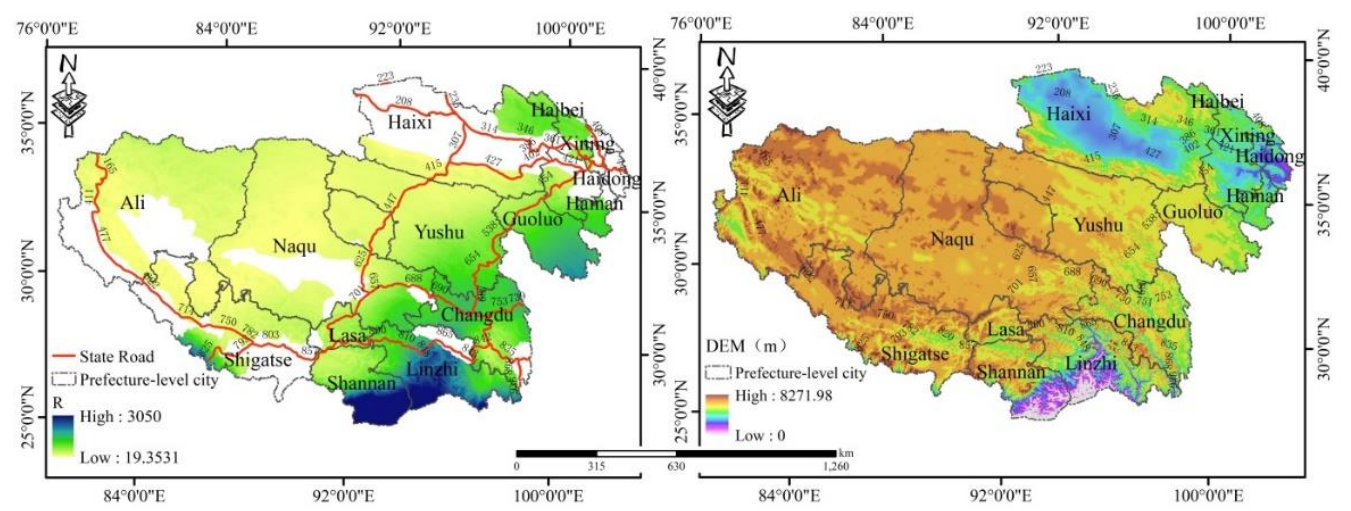

Figure 2 .Distribution map of R factor 
4.1.2 Soil corrosion $(K)$ factor. The $\mathrm{K}$ factor reflected the sensitivity of the soil to erosion, and the $\mathrm{K}$ value was

$$
\begin{aligned}
& \mathrm{K}=0.1317 \cdot\{0.2+0.3 \exp [-0.0256 \operatorname{SAN}(1-S I L / 100)]\} \cdot[\operatorname{SIL} /(C L A+\operatorname{SIL})]^{0.3} \cdot\{1.0-0.25 C /[C+\exp (3.72-2.95 C)]\} \\
& \left.0.7 S N_{I} /\left[S N 1+\exp \left(-5.51+22.9 S N_{I}\right)\right]\right\}
\end{aligned}
$$

In: SAN - Sand grain content, \%; SIL - powder content, \%; CLA - sticky grain content, \%; C - organic carbon content, \%; SN1=1-SAN/100; 0.1317 Conversion factor for U.S. made units to international units.

The results showed that the $\mathrm{K}$ value was 0 $0.081247 \mathrm{t} \cdot \mathrm{hm}^{2} \cdot \mathrm{h} / \mathrm{hm}^{2} \cdot \mathrm{MJ} \cdot \mathrm{mm}$, indicating that the soil in the study area had less corrosion. At the same time, the spatial distribution of $\mathrm{K}$ value had no obvious zone law,

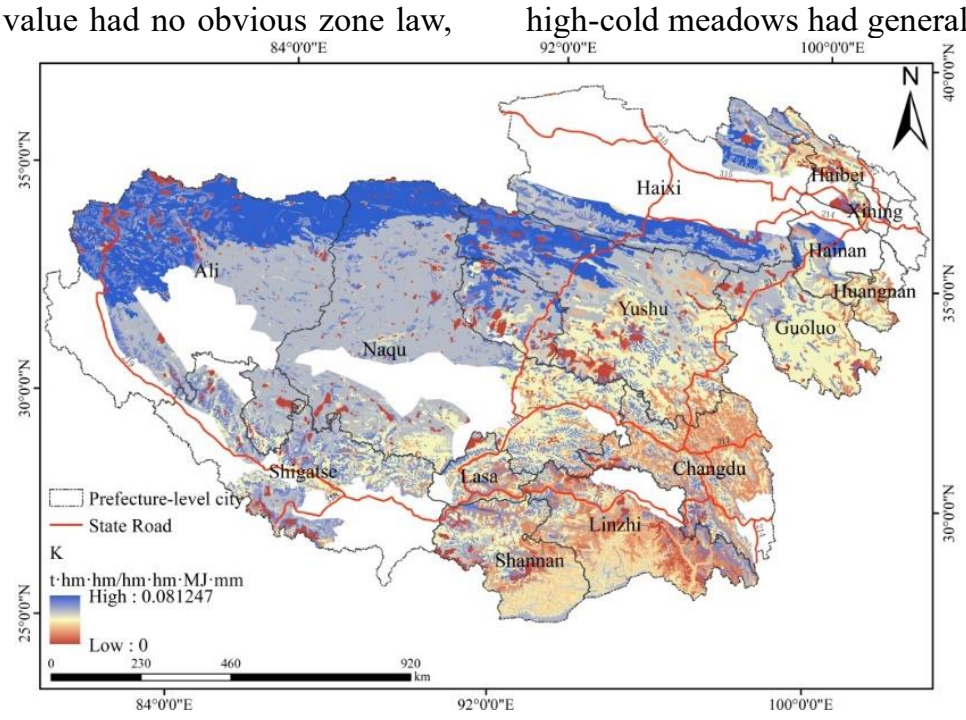

Figure 3 .Distribution map of K factor

4.1.3 Slope Length (LS) Factor. Slope length slope factor LS can reflect the role of topographical factors in the process of soil erosion. Based on the need for reliability and accuracy of data sources, the slope factor of DEM data was extracted by GIS spatial analysis. It can be seen in Figure 4 about the factor distribution ${ }^{[10]}[11]$ :

$$
\mathrm{LS}=\left(\frac{1}{22.1}\right)^{\mathrm{m}}\left(65.21 \sin \theta^{2}+4.56 \sin \theta+\right.
$$

and the whole was characterized by patch distribution. The $\mathrm{K}$ value near the existing national road network was mostly $0.04 \mathrm{t} \cdot \mathrm{hm}^{2} \cdot \mathrm{h} / \mathrm{hm}^{2} \cdot \mathrm{MJ} \cdot \mathrm{mm}$, and the soil near the road network was low corrosion. Geographically, and the value of $\mathrm{K}$ was higher in the area around Golmud, Ali and the northern part of Naqu. That was, areas with high Kvalues were generally sandy and land-degradation areas, while the South-East regions with wide distribution of high-cold meadows had generally lower K-values.
In: LS-Slope length factor; 1-Slope length $(\mathrm{m}) ; \theta$ Gradient $\left(^{\circ}\right)$; m-Function with slope change, $\theta<0.57^{\circ}$, $\mathrm{m}=0.2 ; 0.57^{\circ} \leq \theta<1.72^{\circ}, \mathrm{m}=0.3 ; 1.72^{\circ} \leq \theta<2.86^{\circ}, \mathrm{m}=0.3$; $\theta \geq 2.86^{\circ}, \mathrm{m}=0.5$.

After calculating the GIS grid, the LS distribution was basically consistent with the topography and altitude distribution in the region (Figure 4), which showed the characteristics of high on both sides of the middle and low, especially in the southeast. LS factor values were mainly concentrated in areas less than 5, accounting for $72.08 \%$ of the region's area, and $16.6 \%$ of the region smaller than 15 , and $6.61 \%$ between $10-15$ and $5-10$, respectively.

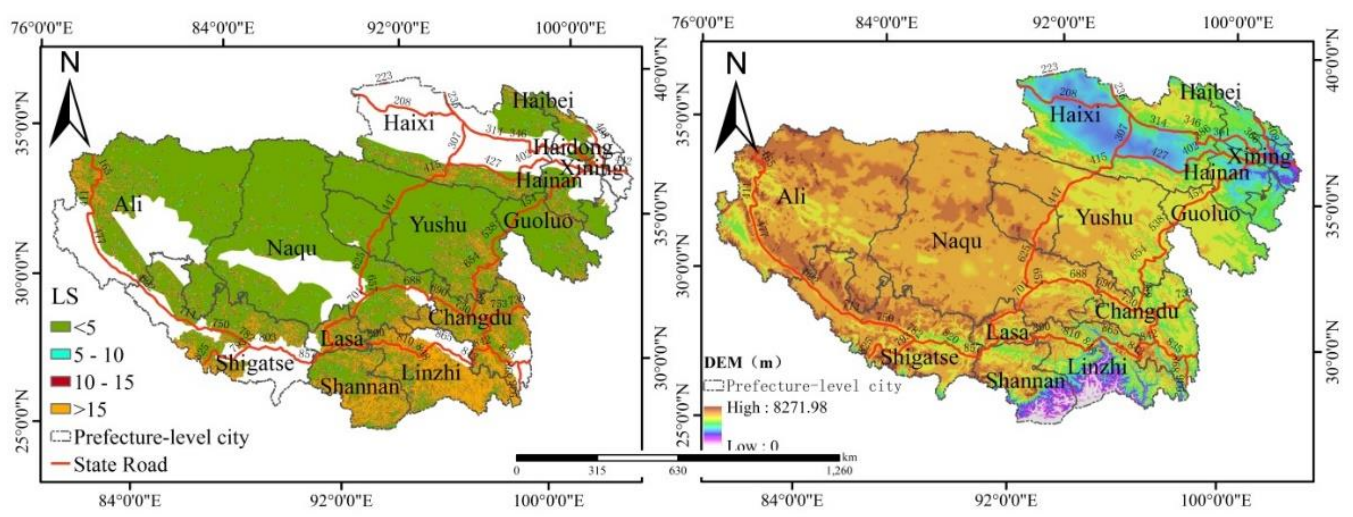

Figure 4 .Distribution map of LS factor 
Table 2 .Area and scale of different LS

\begin{tabular}{cccc}
\hline Serial number & LS & The corresponding floor space $/ \mathrm{km}^{2}$ & Percentage $\%$ \\
\hline 1 & $<5$ & 1003621 & 72.08 \\
2 & $5-10$ & 65509 & 4.70 \\
3 & $10-15$ & 92089 & 6.61 \\
4 & $>15$ & 231130 & 16.60 \\
\hline
\end{tabular}

4.1.4 Vegetation cover and management (C) factor. In addition to the forest distribution in the permafrost area of the Qinghai-Tibet Plateau, the vegetation in most areas was mainly high-cold meadows and high-cold desert grasslands, and the vegetation coverage was very low. As the protection factor of the erosion process, the $\mathrm{C}$ factor reflected the protective effect of vegetation condition on the surface, the better of vegetation condition, the smaller the $\mathrm{C}$ value. In this paper, the vegetation cover was calculated using Normalized Difference Vegetation Index and the $\mathrm{C}$ value was estimated based on the range of vegetation cover. It can be seen in Figure 5 about the distribution of $\mathrm{C}$ values:

$$
\begin{gathered}
\mathrm{f}=\frac{N D V I-N D V I}{\min } \\
\mathrm{C}=\left\{\begin{array}{c}
\mathrm{NDI}_{\max }-\mathrm{NDVI}_{\min } \\
10 \leq \mathrm{f}<0.1 \% \\
0.6508-0.3436 \times \lg (\mathrm{f}) 0 \leq \mathrm{f}<78.3 \% \\
\text { of } \geq 78.3 \%
\end{array}\right.
\end{gathered}
$$

Type: f- Vegetation cover (\%); NDVI - Normalized Difference Vegetation Index, no volume outline; NDVI $\max$ - The maximum value of NDVI in the study area;

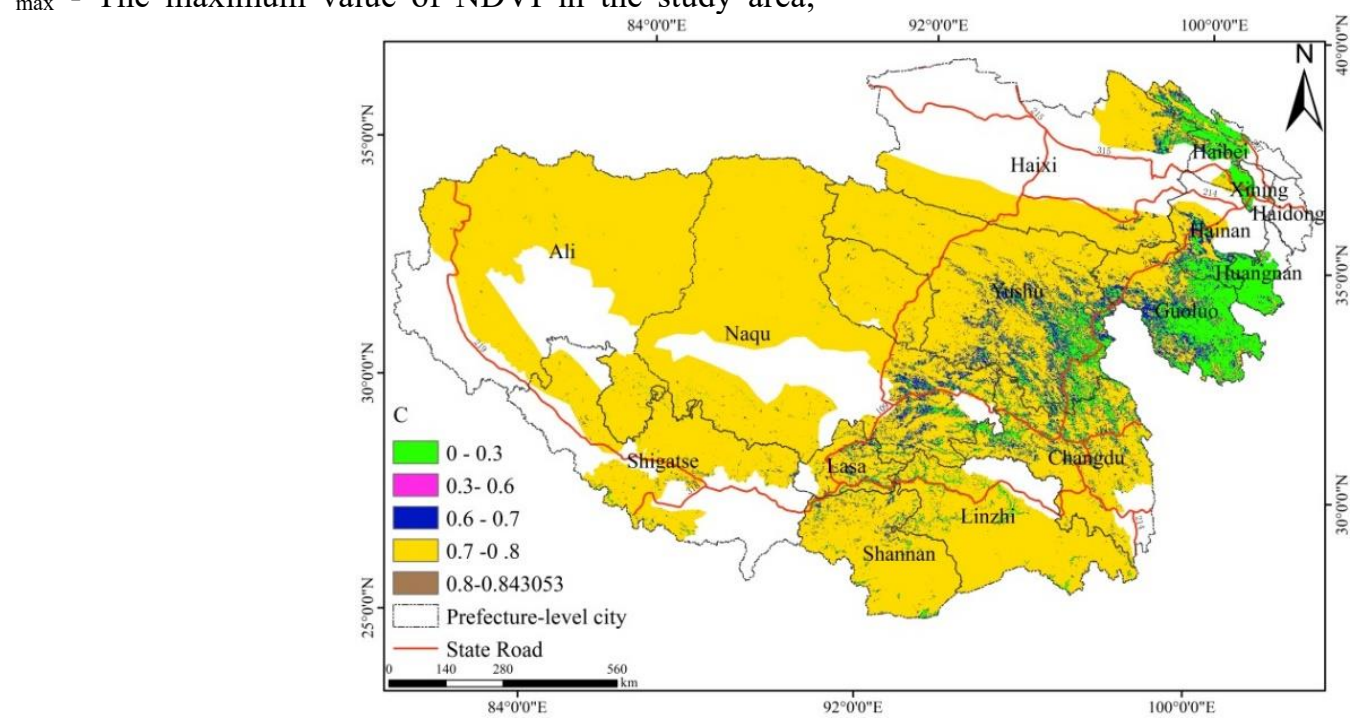

Figure 5 .Distribution map of C factor

Table 3 .Area and scale of different C

\begin{tabular}{cccc}
\hline $\begin{array}{c}\text { Serial } \\
\text { number }\end{array}$ & $\mathrm{C}$ & Area $/ \mathrm{km}^{2}$ & $\begin{array}{c}\text { Percentag } \\
\mathrm{e} \%\end{array}$ \\
\hline 1 & $0-0.3$ & 101107 & 7.26 \\
2 & $0.3-0.6$ & 0 & 0.00 \\
3 & $0.6-0.7$ & 91826 & 6.60 \\
4 & $0.7-0.8$ & 1198905 & 86.13 \\
5 & $0.8-0.803053$ & 87 & 0.01 \\
\hline
\end{tabular}

NDVI min - The minimum value of NDVI in the study area. It is shown in Figure 5 that the $\mathrm{C}$ factor value was between $0-0.843053$, and the average value was 0.6851 , indicating that the overall vegetation cover of the area was low. The $\mathrm{C}$ factor in the region was mainly distributed between $0.7-0.8$, less in the range of $0.8-0.843053$, not in the range of $0.3-0.6$, the comprehensive reflection of the region's vegetation distribution was consistent with the field survey. From the spatial distribution point of view, the $\mathrm{C}$ value between $0-0.3$ was mainly distributed in Qinghai Golo, Huangnan, Haibei Autonomous Prefecture and Xining near, and in The Tibetan Yushu State, Nyingchi region scattered distribution.

It can be seen in Table 3 about the area and proportion of the different range values of the $\mathrm{C}$ factor. We can observed that only $7.26 \%$ of the area was less than 0.3 , and $6.6 \%$ was between $0.6-0.7$, and $86.13 \%$ was between $0.7-0.8$, and $0.01 \%$ of the total area in areas greater than 0.8 . There were no areas between 0.3-0.6. From the area distribution, the vegetation in the permafrost area of the Qinghai-Tibet Plateau had the tendency of degradation succession, and the overall vegetation cover was poor.
4.1.5 Water and soil conservation measures $(P)$ factors. Water and soil conservation measure stake $\mathrm{P}$ was the ratio of soil loss and soil loss of slope-dwelling plots without water conservation measures, $P$ value between 0 1,0 value indicated no soil erosion after the measures of soil and water conservation are taken, and 1 value indicated that the soil and water conservation measures were completely ineffective and there was no outline. It is 
shown in Figure 6 and Table 4 that the P value was mainly distributed between $0.8-1$, accounting for $69.45 \%$ of the total area, followed by $\mathrm{p}$ value distribute between $0.1-0.4$, accounting for $13.59 \%$ of the total area, and the region of less than 0.1 was the smallest, only $7.6 \%$.

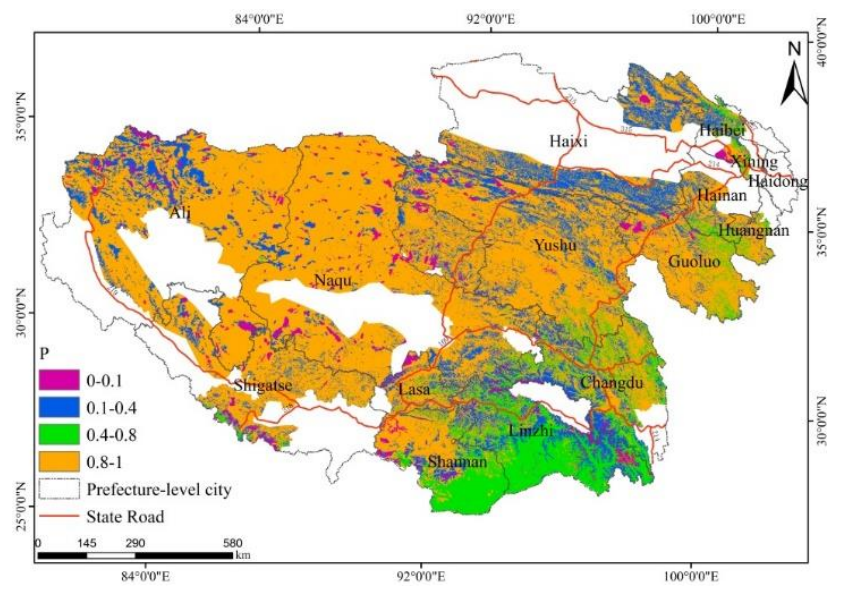

Figure 6 .Distribution map of $\mathrm{P}$ factor

4.2.2 Table 5), and were classified into a total of 6 levels of mired, mild, moderate, intensity, very strong and acute soil erosion from small to large. It is shown in Figure 7
Table 4 . Area and scale of different P

\begin{tabular}{cccc}
\hline $\begin{array}{c}\text { Serial } \\
\text { number }\end{array}$ & $\mathrm{P}$ & Area $/ \mathrm{km}^{2}$ & $\begin{array}{c}\text { Percentage } \\
\%\end{array}$ \\
\hline 1 & $0-0.1$ & 105766 & 7.60 \\
2 & $0.1-0.4$ & 189011 & 13.59 \\
3 & $0.4-0.8$ & 130098 & 9.35 \\
4 & $0.8-1$ & 965880 & 69.45 \\
\hline
\end{tabular}

\subsection{Analysis of soil erosion characteristics}

4.2.1 Spatial analysis of soil erosion intensity. Using ArcGIS space analysis, the soil erosion module in the permafrost area of the Qinghai-Tibet Plateau was calculated to be between $0-470543 \mathrm{t} / \mathrm{km}^{2} \cdot \mathrm{a}$, with an average of $6661.43 \mathrm{t} / \mathrm{km}^{2}$ - a (Figure 7). In order to standardize and facilitate comparison with other regions, the calculated soil erosion modules were graded according to the Soil Erosion Classification Standard (SL190-2007)

and Figure 8 about the spatial distribution map of soil erosion module and scale of erosion intensity in the permafrost area of the Qinghai-Tibet Plateau:

Table 5 .Grading standard of soil erosion

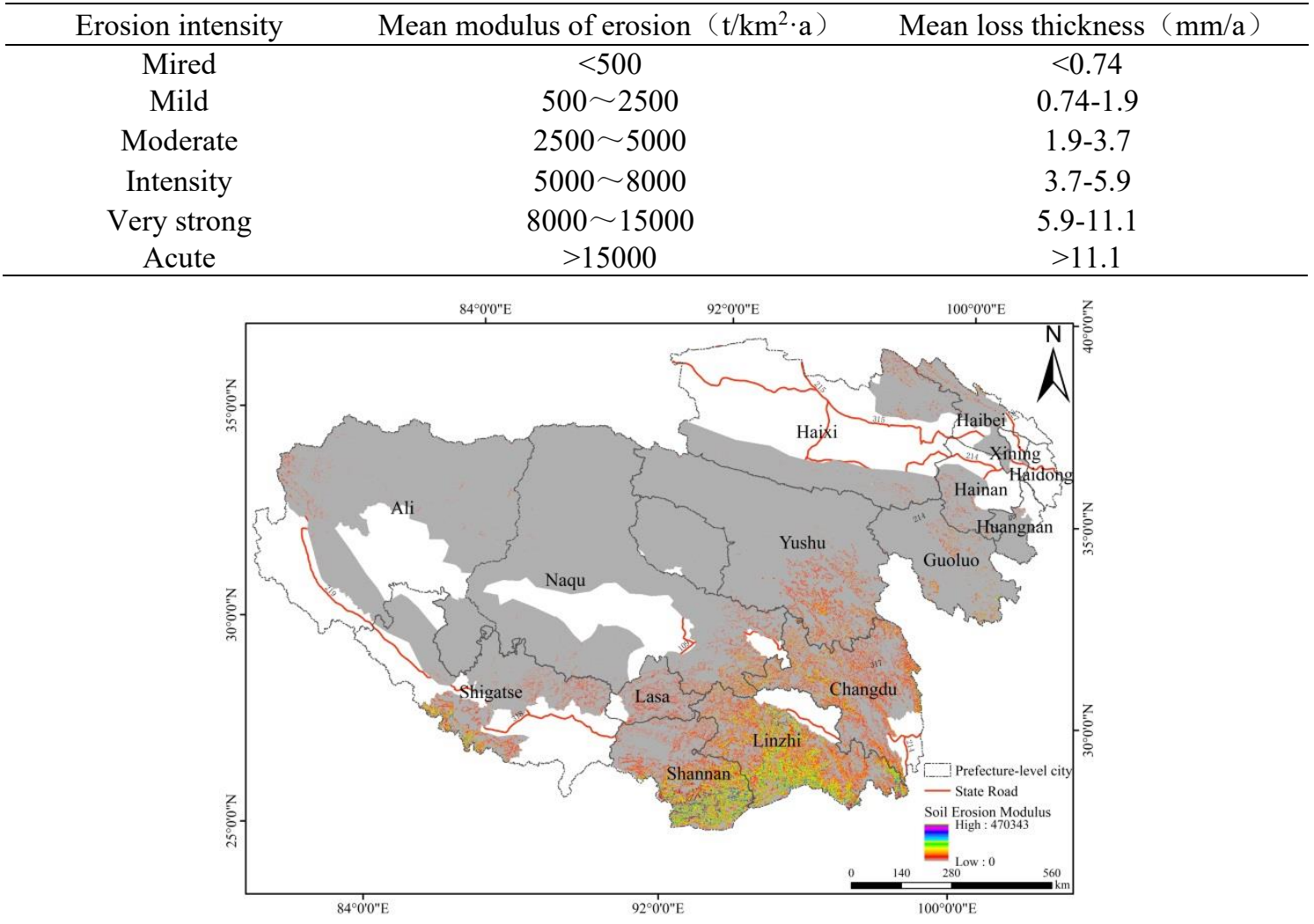

Figure 7 .Spatial distribution map of soil erosion modulus 


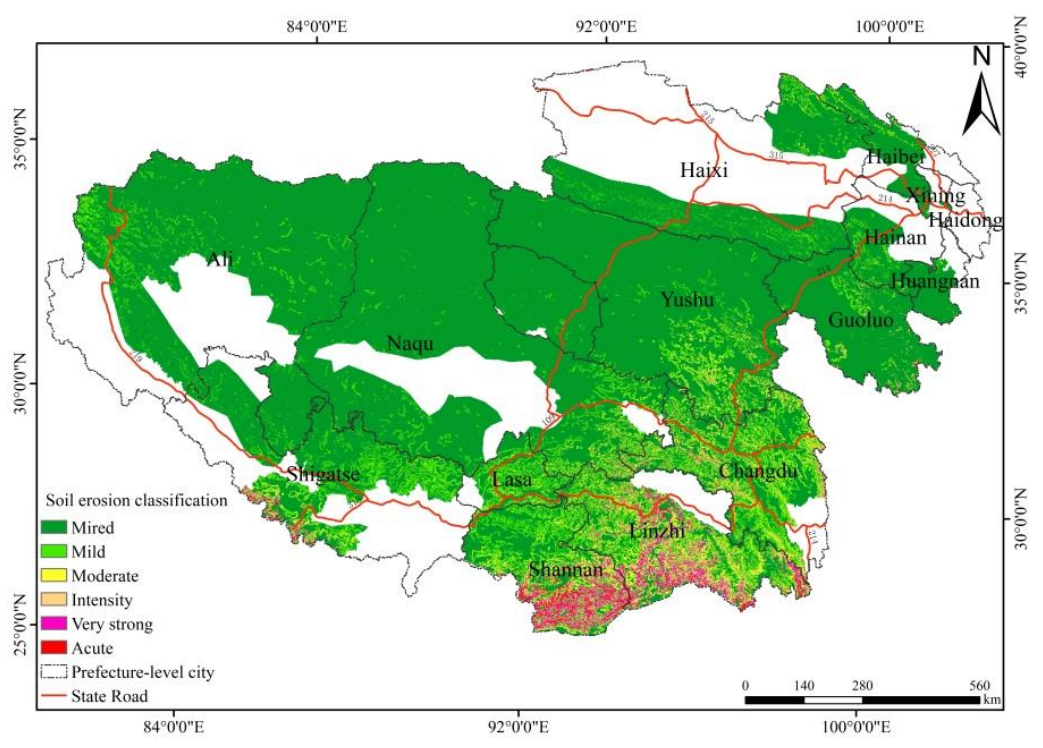

Figure 8 .Soil erosion intensity classification map

It can be seen in Figure 7 and Figure 8 that the erosion modules of the study area covered all erosion intensity. From the spatial distribution point of view, the intensity of erosion gradually weakened from south to north, and the acute erosion was mainly distributed in the Shigatse region, Lhasa City, Changdu region and the northern part of shannan in the southern part of the Qinghai-Tibet Plateau. And the soil erosion intensity in the permafrost area of the Qinghai-Tibet Plateau was mainly mired and mild, accounting for $63.29 \%$ and $12.73 \%$ of the total area, respectively, mainly concentrated in the high plains.

4.2.4 Table 6 that the average erosion mode increases with the increase of LS value, which shows that LS had a strong positive correlation with regional soil erosion module. Most of the areas with less than 5 LS were plain areas, with an average erosion module of $474 \mathrm{t} / \mathrm{km}^{2} \cdot \mathrm{a}$, accounting for $72.12 \%$. LS value was between 10 and 15 or above 15 , the erosion intensity reached extremely strong and intense, although the area of severe erosion was small, but the average erosion module was larger, reaching $54038 \mathrm{t} / \mathrm{km}^{2} \cdot \mathrm{a}$.
Intensity, very strong, acute erosion area accounted for $4.91 \%, 3.43 \%, 11.26 \%$ of the total area, and mostly distributed in the uneven terrain of the region, and mainly concentrated in the southern part of the study area, the Himalayas, the Cross Mountains and the Tangula Mountain on both sides of the area, followed by the concentration of more human activities around the city.

\subsubsection{Relationship between LS and soil erosion intensity. It is shown in}

Table 6 .Erosion intensity area scale of different LS factors

\begin{tabular}{cccc}
\hline LS & Area $/ \mathrm{km}^{2}$ & $\begin{array}{c}\text { Area } \\
\text { proportion } \%\end{array}$ & $\begin{array}{c}\text { Mean soil erosion modulus } \\
\mathrm{t} / \mathrm{km}^{2 * a}\end{array}$ \\
\hline$<5$ & 1002129 & 72.12 & 474.97 \\
$5 \sim 10$ & 65341 & 4.7 & 6689.62 \\
$10 \sim 15$ & 91845 & 6.61 & 11230.04 \\
$>15$ & 230145 & 16.56 & 34813.53 \\
\hline
\end{tabular}

\subsection{Analysis of erosion factor gray correlation based on RUSLE results}

In order to further study the correlation between soil erosion A values and factors R, K, LS, C and P in the permafrost area of the Qinghai-Tibet Plateau, the main factors affecting A values were analyzed by gray correlation.
4.3.1 Grayscale Association Analysis .The basic idea of gray association analysis was to determine the degree of geometric similarity between the curves made up of the comparison series and the curves made up of the reference series, and to determine the degree of similarity between the combined series and the reference series to make up the curve, the more similar the shape, the greater the degree of association ${ }^{[12]}$. 
(1) Determine the processing data

Reference series (master sequence) was $\mathrm{A}$, and comparing series (sub-series) were R, K, LS, C, and P.

(2) No volumeization of reference and comparison columns

Because the data size scale and volume outline were different, first of all, the meanization and normalizing methods were adopted to deal with the data without volume.

Meaning processing:

$x_{i}(k)=\frac{x_{i}(k)}{\overline{x_{i}}}, k=1,2, \ldots n ; i=0,1,2, \ldots m$

$\mathrm{n}$ - Sample number, take the value of 1-55732; m Reference and comparison series, reference number listed as 0 , comparison number listed as 1-5.

(3) Find the gray correlation coefficient of the reference series and the comparison series $\xi$

The association coefficient can be simplified as the following formula:

Association coefficient:

$\varepsilon_{i}(k)=\frac{\min _{i} \min _{k}\left|x_{0}(k)-x_{i}(k)\right|+\rho \min _{i} \min _{k}\left|x_{0}(k)-x_{i}(k)\right|}{\left|x_{0}(k)-x_{i}(k)\right|+\rho \min _{i} \min _{k}\left|x_{0}(k)-x_{i}(k)\right|}$

$\rho$ - The resolution coefficient, the value range $0-1$. The smaller the value, the more significant the difference in the association coefficient

(4) Seek relevance

Calculate relevance:

$$
\gamma_{0 i}=\frac{1}{m} \sum_{k=1}^{m} \varepsilon_{i}(k)
$$

The closer the value of the $\gamma 0 \mathrm{i}$ to 1 , the better the correlation.

4.3.2 Grayscale associated analysis results. Combined with the study of soil erosion distribution in the permafrost area of the Qinghai-Tibet Plateau and the gray correlation analysis results of RUSLE model, the correlation between R, K, LS, C and A values were 0.883 , $0.843,0.921,0.851,0.848$. The four factors most relevant to erosion mode were LS, R, C and P, of which R was the driving factor, and the $\mathrm{R}$ factor was not considered from the point of view of the selection of the project line. The effects of LS, C and P on soil erosion should be considered.

\section{Soil and water conservation ecological protection zoning}

\subsection{Zoning basis and key metrics}

Combined with the soil erosion characteristics and the basic conditions of ecological protection in the permafrost area of the Qinghai-Tibet Plateau mentioned above, the three indicators of land use, vegetation cover ( $\mathrm{C}$ value) and soil erosion intensity were selected, and the ecological protection in the region was defined as three levels from priority to difficulty, and divided into five grades.

Priority levels, divided into two levels: the slope protection of this area should give priority to ecological protection measures, the determination of conditions were: (1)land use were grassland, forest land and arable land; (2) The native vegetation coverage was greater than $75 \%$ $(\mathrm{C}<0.3)$ or the soil erosion intensity was mired and mild.
According to the results of GIS analysis, the priority level of meeting three conditions was high, namely, land use were grassland, forest land, arable land, native vegetation cover was greater than $75 \%(C<0.3)$ and soil erosion intensity was mired, mild, defined as 1 . Meet the land use for grassland, forest land, arable land, native vegetation cover of more than $75 \%(C<0.3)$ or soil erosion intensity was mired, mild area was 2 .

Appropriate level: This area had the conditions for ecological protection, but should carry out adaptive analysis and cooperate with certain management measures during the construction process, the conditions were: land use for grassland, forest land, arable land, and the native vegetation coverage was between $37 \%$ and $74 \%(0.8>\mathrm{C}$ $>3$ ) and soil erosion intensity was mired, mild area was 3 .

Difficulty level, divided into two levels: this area did not have the basic conditions for ecological protection or ecological protection was difficult to determine. And the determination conditions were: land use for unused land (including 61 sand, 62 Gobi, 63 saline land, 64 marshes, 65 bare land, 66 bare rock texture, 67 high desert, tundra); The native vegetation coverage was less than $37 \%(1>\mathrm{C}$ $>0.8$ ) and the soil erosion was very strong and acute. Meet any of the three conditions was 4 . At the same time, two of the above three conditions were particularly difficult areas, defined as 5 .

Table 7.Area and scale of different grades

\begin{tabular}{ccc}
\hline Grade & Area $/ \mathrm{km}^{2}$ & Percentage \% \\
\hline 1 & 91795 & 6.61 \\
2 & 677596 & 48.77 \\
3 & 145636 & 10.48 \\
4 & 454492 & 32.71 \\
5 & 19941 & 1.44 \\
\hline
\end{tabular}

It can be seen in Table 7 that the slope protection level for Qinghai-Tibet Plateau permafrost area belonged to the first 2 grade of the largest area, accounting for 48.77 percent of the whole area, mainly distributed in Qinghai Yushu and Guoluo, Tibet Ali region. This was followed by the 4 th grade, which accounted for $32.71 \%$ of the region, mainly in the southern part of Qinghai-West China and the southeastern part of Tibet. Areas with special hardship protection rating occupied the smallest area of space.

\section{Conclusion}

In this paper, the multi-year permafrost area of the Qinghai-Tibet Plateau was used as the research area, combined with GIS, RUSLE and gray correlation analysis, the soil erosion characteristics and soil and water conservation ecological protection zoning in the permafrost area of the Qinghai-Tibet Plateau were studied. The research showed that the erosion intensity in the permafrost area of the Qinghai-Tibet Plateau was mainly mired and mild, accounting for $63.29 \%$ and $12.73 \%$ 
respectively. The $\mathrm{R}$ value was at 19.3531-3050 $\mathrm{MJ} \cdot \mathrm{mm} / \mathrm{hm}^{2} \cdot \mathrm{h} \cdot \mathrm{a}$. Overall the south was higher than the north, the east was higher than the west, and the peak was in the southern part of the Cuona county. $\mathrm{K}$ value was between 0 and $0.081247 \mathrm{t} \bullet \mathrm{hm}^{2} \cdot \mathrm{h} / \mathrm{hm}^{2} \cdot \mathrm{MJ} \cdot \mathrm{mm}$. It was in a patchy distribution, with low soil erodibility. The area with an LS value of less than 5 accounted for $72.08 \%$. Large areas with a $\mathrm{C}$ value of $0.7-0.8$, the overall vegetation cover of the area was low. The correlation between LS, C and P factors and erosion modules were high, so it was an effective method to reduce soil erosion by selecting lines, improving vegetation coverage and laying effective soil and water conservation measures in the construction activities of the permafrost area of the Qinghai-Tibet Plateau. Selecting land use, vegetation cover, soil erosion intensity as three index layers, and the ecological protection in the region was defined as three levels from priority to difficulty, and divided into five grades.

Theoretical research results will have important theoretical and technical significance for the prevention and control of soil erosion of highway slope in the permafrost area of the Qinghai-Tibet Plateau.

\section{Authors}

First author: Xiaofeng Zhang (1975 -) male, native place: Jilin, associate researcher, doctor, research direction: environment and water conservation in transportation. Email: 14644896@qq.com

Corresponding author: Jinru $\mathrm{Hu}$ (1982 -) female, native place: Shanxi, senior engineer, research direction: Soil and water conservation in transportation. E-mail: hjr158@126.com

\section{References}

1. Xiao Yu, Xie Gaodi ,Ankai. Qinghai-Tibet Plateau Ecosystem Soil Conservation Function and Its Value [J].Acta Oecologica, 2003, 23(11): 2367-237.

2. Yu Ge, Lu Chunxia, Xie Gaodi. Experimental study on the soil retention function and value of high cold meadow in the northern edge of the Qinghai-Tibet Plateau [J]. Journal of Beijing Forestry University, 2006, 28 (4): 57-61

3. Cheng Zhigang, Liu Xiaodong, Fan Guangzhou, etc. Assessment of climate change in the 21 st century Qinghai-Tibet Plateau [J]. Drought Zone Study, 2011 (4): 669-676.

4. Luo LiFang, Zhang Keli, Kong Yaping, etc. The different characteristics of soil erosion in the QinghaiTibet Plateau region [J]. Journal of Soil and Water Conservation, 2004 (1):58-62.

5. Wu Shaohong, Yu Yunhe, Zheng Du, et al. Climate Change Trends in the Qinghai-Tibet Plateau in the Last 30 Years [J].Geography Journal, 2005, 60 (1): 311.

6. Shabanov N, Zhou L, Knyazikhin Y, et al. Analysis of inter-annual changes in northern vegetation activity observed in AVHRR data From 1981 to 1994 . IEEE Transactions on Geoscience and Remote Sensing, 2002, 40(1):115-130.

7. Song Yi, Ma Mingguo. Analysis of vegetation cover changes in northwest China based on SPOT VEGETATION data. Desert China, 2007, 1 (1):89-93

8. Kang Linqi, Zhou Tiancai, Yu Youmin, etc. 19842013 Qinghai-Tibet Plateau soil erosion space-time change characteristics[J]. Journal of Applied and Environmental Biology, 2018, 24 (2): 245-253.

9. He Shaolang, Li Fengying, He Xiaowu. Advances in the study of rainfall erosion in water erosion forecasts[J]. Water and soil conservation bulletin, 2018, v.38; No.223 (02): 268-276.

10. $\mathrm{Wu}$ Wei, Study on the soil erosion characteristics of the right-wing middle flag in Koryu, Inner Mongolia[D].Inner Mongolia Agricultural University,2012.

11. Lin Huilong, Zheng Shuting, Wang Xuelu. Evaluation of soil erosion in the high-cold grasslands of Sanjiangyuan based on the RUSLE model[J]. Journal of grass industry,2017,26(07):11-22.

12. Deng Julong. Greyforecast anddecision [M]. Wuhan: Huazhong University of Scientific and TechnologyPress, 1987: 12-331. 